\title{
Hypoxia and hydrothoraces in a case of liver cirrhosis: correlation of physiological, radiographic, scintigraphic, and pathological findings
}

\author{
N. N. STANLEY, A. J. WILliamS, C. A. DEWAR, L. M. BLENDIS, AND LYNNE REID \\ From the Department of Medicine, The Middlesex Hospital, Mortimer Street, London WIN 8AA, the \\ Department of Gastroenterology, Central Middlesex Hospital, London NW10 7NS, and the \\ Department of Experimental Pathology, Cardiothoracic Institute, Brompton Hospital, London SW3
}

Stanley, N. N., Williams, A. J., Dewar, C. A., Blendis, L. M., and Reid, Lynne (1977). Thorax, 32, 457-471. Hypoxia and hydrothoraces in a case of liver cirrhosis: correlation of physiological, radiographic, scintigraphic, and pathological findings. A case is reported of liver cirrhosis complicated by cyanosis and recurrent right hydrothorax. A diagnostic pneumoperitoneum demonstrated that direct movement of ascites through a diaphragmatic defect was responsible for the hydrothoraces. Pulmonary function tests between episodes of hydrothorax showed severe arterial hypoxaemia, a $23 \%$ right-to-left shunt, and a reduction in the carbon monoxide transfer factor to less than half of the predicted value. Evidence of abnormal intrapulmonary arteriovenous communications was obtained by perfusion scanning. At necropsy the central tendon of the diaphragm showed numerous areas of thinning which were easily ruptured. Injection of the pulmonary arterial tree demonstrated precapillary arteriovenous anastomoses and pleural spider naevi. A morphometric analysis provided quantitative evidence of pulmonary vasodilatation limited to the intra-acinar arteries, consistent with the effect of a circulating vasodilator. The scintigraphic and pathological findings suggested that shunting had been greater in the right than the left lung. Examination of thin lung sections by light microscopy showed that the walls of small veins were thickened, and electron microscopy showed that this was due to a layer of collagen. The walls of capillaries were similarly thickened, which caused an approximately two-fold increase in the minimum blood-gas distance and contributed to the reduction in transfer factor.

Two respiratory complications may dominate the clinical picture in patients with liver cirrhosis. Some are deeply cyanosed due to a complex disorder of gas exchange. This includes right to left shunting (Georg et al., 1960), ventilation-perfusion inequality (Cotes et al., 1968) and reduction in the transfer factor (Stanley and Woodgate, 1972). Gross abnormalities of the pulmonary circulation may be revealed by perfusion scanning (Stanley et al., 1972) and during postmortem examination of the lung vasculature (Berthelot et al., 1966). Other patients develop hydrothoraces which are often massive, recurrent and unilateral (Frothingham, 1942). This paper presents a comparison of physiological, isotopic and necropsy findings in a case of liver cirrhosis with hypoxaemia and recurrent hydrothorax and provides some further insight into their cause.

\section{Case report}

The patient, a woman of 45 years, was first admitted to the Central Middlesex Hospital in July 1973 with a four-week history of jaundice, dark urine, and pale stools. There had been no abdominal pain, but her alcohol intake had been excessive and she had been treated with methyldopa since the diagnosis of mild hypertension one year earlier. She had smoked approximately 10 cigarettes per day. On physical examination there 
was moderate hepatomegaly. Laboratory investigations revealed an obstructive jaundice (serum bilirubin $720 \mu \mathrm{mol} / 1$, aspartate transaminase 63 $\mathrm{IU} / \mathrm{ml}$, and alkaline phosphatase $184 \mathrm{IU} / \mathrm{ml}$ ) with a negative mitochondrial antibody test. Laparotomy revealed no anatomical defect of the biliary system and an operative cholangiogram was normal. A liver biopsy showed an advanced micronodular cirrhosis. Postoperatively she developed ascites, but this resolved after salt restriction and administration of a diuretic. Her cirrhosis was presumed to be due to chronic alcoholism. The cause of the cholestasis was uncertain but was possibly related to the methyldopa therapy (Toghill et al., 1974). After stopping the use of this drug her blood pressure remained normal and the jaundice gradually disappeared.

She was readmitted in June 1974 with an acute onset of dyspnoea due to a massive right-sided hydrothorax. There was also mild ascites and ankle oedema. The pleural fluid had the characteristics of a transudate. Its protein concentration was $0.25 \mathrm{~g} / \mathrm{l}$; light microscopy revealed only mesothelial cells and bacterial cultures produced no growth. A pleural biopsy and bronchoscopy showed no abnormality. After an initial 1.51 thoracentesis she was given more intensive diuretic therapy and the hydrothorax disappeared. In September and November 1974 she had two further admissions due to recurrent right-sided hydrothoraces; on both occasions there was acute respiratory distress. Between these episodes she experienced moderate dyspnoea on effort, even though physical and radiographic examinations of the chest were normal. During the November admission she was noticed to be cyanosed and to have finger clubbing. There were no abnormal heart sounds and the electrocardiogram was normal. The cyanosis persisted after her chest radiograph had returned to normal; physiological studies and a lung scan performed at this time are described below.

In January 1975 she had a fourth right-sided hydrothorax, and one week later, when it had largely been absorbed, she was investigated by means of a diagnostic pneumoperitoneum. After 1 litre of air had been introduced into the peritoneal cavity she experienced a 'bubbling' sensation behind the sternum which persisted for 45 minutes. A chest radiograph two minutes after peritoneal air injection showed no air above the diaphragm, but another obtained after one hour showed a large pneumothorax. These findings suggested that a pleuroperitoneal communication was responsible for the hydrothorax. In an attempt to prevent its recurrence a pleurodesis was induced $\stackrel{\overrightarrow{\vec{B}}}{\overrightarrow{\vec{D}}}$ by insufflating iodised talc into the right pleural space. After this there was a remission for six $\frac{C}{0}$ months, but in August 1975 she developed a fifth large hydrothorax on the right side. Once again it $\overline{\mathbb{D}}$ disappeared after thoracentesis and readjustment $\stackrel{\Omega}{\Omega}$ of the diuretic therapy. Her condition gradually $\infty$ deteriorated thereafter. Six further episodes of $\overrightarrow{0}$ right-sided hydrothorax occurred in the next nine $\vec{\overrightarrow{ }}$ months, and moderate oedema, ascites, and en- $\vec{\omega}$ cephalopathy became intractable features. In May $\overrightarrow{\vec{*}}$ 1976 she was readmitted and died in hepatic coma.

\section{Pulmonary function tests}

\section{METHODS}

The forced expiratory volume in one second and the forced vital capacity were measured using a low resistance dry spirometer. Intrathoracic gas volumes were determined by the helium dilution $\stackrel{\odot}{\rightarrow}$ method and the carbon monoxide transfer factor $\vec{\varphi}$ (TF) by the single breath technique (Ogilvie et al., $\searrow$ 1957). Arterial $\mathrm{O}_{2}$ tension $\left(\mathrm{PaO}_{2}\right), \mathrm{CO}_{2}$ tension $\left(\mathrm{PaCO}_{2}\right)$, and $\mathrm{pH}$ were measured with appropriate electrodes (Radiometer E 5046, E 5036 and G 297). The $\mathrm{O}_{2}$ and $\mathrm{CO}_{2}$ electrodes were calibrated using humidified gases of known composition and $\frac{\circ}{\mathbb{D}}$ the measured $\mathrm{PaO}_{2}$ was corrected for the $\mathrm{O}_{2}$ elec- $\stackrel{\varrho}{\square}$ trode's blood-gas factor (1.06) which had been $\overrightarrow{\overrightarrow{0}}$ determined by tonometry. Using standard tech- 3 niques and calculations, described in detail elsewhere (Stanley and Woodgate, 1971), the alveolararterial $\mathrm{O}_{2}$ tension difference $\left(\mathrm{A}-\mathrm{ADO}_{2}\right)$ was measured while she breathed room air. The $\frac{O}{9}$ $\mathrm{A}-\mathrm{ADO}_{2}$ was also measured after 15 minutes $\times$ breathing $100 \% \mathrm{O}_{2}$ and the true shunt was deter- 3 mined as a percentage fraction of the cardiac output assuming an arteriovenous $\mathrm{O}_{2}$ content $\frac{\mathrm{O}}{3}$ difference of 2.9 vol \%, which was the average value in 12 other cases of cirrhosis with finger $\frac{}{7}$ clubbing (Stanley and Woodgate, 1971). Observed $\frac{D}{O}$ values were compared with predicted normal values for lung volumes and TF given by Cotes $N$ (1975), and with gasometric data previously obtained by the authors in healthy control subjects using the same techniques.

\section{RESULTS}

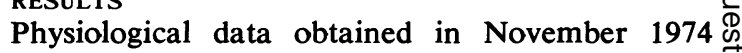
when no pleural fluid was seen in the chest radiograph are listed in Table 1. The lung volumes were normal, which excluded any major restric- $\overrightarrow{\mathbb{D}}$ tive or obstructive ventilatory defects, but the TF $\stackrel{\rho}{\mathbb{P}}$ was very low. Arterial blood analysis showed severe $\frac{\varrho}{\sigma}$ hypoxaemia in spite of a respiratory alkalosis. The 
Table 1 Pulmonary function tests

\begin{tabular}{|c|c|c|}
\hline & Observed & Predicted \\
\hline$\frac{\text { Forced expiratory volume in one sec }}{\text { Forced vital capacity }}$ & $81 \%$ & $81 \%$ \\
\hline $\begin{array}{l}\text { Total lung capacity (l) } \\
\text { Functional residual capacity (l) } \\
\text { Residual volume (l) } \\
\text { Transfer factor }(\mathrm{mmol} \mathrm{min}-1 \mathrm{kPa})\left(\mathrm{ml} \mathrm{min}^{-1} \mathrm{~mm} \mathbf{~ g g}\right) \\
\text { Arterial } \mathrm{O}_{2} \text { tension }(\mathrm{kPa})(\mathrm{mm} \mathrm{Hg}) \\
\text { Arterial } \mathrm{CO}_{2} \text { tension }(\mathrm{kPa})(\mathrm{mm} \mathrm{Hg}) \\
\text { Arterial pH } \\
\text { Plasma bicarbonate }\left(\mathrm{mmol} 1^{-1}\right) \\
\text { Alveolar-arterial } \mathrm{O}_{2} \text { tension difference breathing room air }(\mathrm{kPa})(\mathrm{mm} \mathrm{Hg}) \\
\text { Alveolar-arterial } \mathrm{O}_{2} \text { tension difference breathing } 100 \% \mathrm{O}_{2}(\mathrm{kPa})(\mathrm{mm} \mathbf{H g}) \\
\text { True shunt breathing } \mathrm{O}_{2}(\% \text { cardiac output) }\end{array}$ & $\begin{array}{l}4 \cdot 4 \\
1 \cdot 9 \\
1 \cdot 3 \\
4 \cdot 0(12 \cdot 1) \\
7 \cdot 2(54) \\
4 \cdot 1(31) \\
7 \cdot 44 \\
20 \cdot 5 \\
8 \cdot 0(60) \\
38(285) \\
23\end{array}$ & $\begin{aligned} & 4 \cdot 7 \\
& 2 \cdot 4 \\
& 1 \cdot 6 \\
& 8 \cdot 2(24 \cdot 5) \\
& 12 \cdot 2(92) \\
& 5 \cdot 2(39) \\
& 7 \cdot 40 \\
& 24 \cdot 5 \\
&<3 \cdot 3(<25) \\
&<6 \cdot 0(<45) \\
&<3\end{aligned}$ \\
\hline
\end{tabular}

Volumes and transfer factor measured while seated and other values while supine.

$\mathrm{A}-\mathrm{ADO}_{2}$ was considerably increased breathing room air and also when breathing $\mathrm{O}_{2}$, indicating a true shunt estimated to be $23 \%$ of the cardiac output. The gasometric data were obtained in the supine position. The $\mathrm{PaO}_{2}$ rose to $7.8 \mathrm{kPa}(58 \mathrm{~mm} \mathrm{Hg})$ when she lay on the left side but fell to $6.7 \mathrm{kPa}$ $(50 \mathrm{~mm} \mathrm{Hg}$ ) when she turned on to her right side. The $\mathrm{PaCO}_{2}$ did not vary appreciably with body position.

Repeated pulmonary function tests in the next 18 months continued to show normal ventilatory capacity, but the TF remained very low (3.5-3.7 mmol $\left.\min ^{-1} \mathrm{kPa}\right)\left(10 \cdot 6-11.2 \mathrm{ml} \mathrm{min}{ }^{-1} \mathrm{~mm} \mathrm{Hg}\right)$. Interestingly, her hypoxaemia was not exacerbated during episodes of hydrothorax or when her right lung was partially collapsed by the 1 litre pneumothorax after the diagnostic pneumoperitoneum. With the pneumothorax in situ her $\mathrm{PaO}_{2}$ was $8.7 \mathrm{kPa}(64 \mathrm{~mm} \mathrm{Hg})$ and fell to $7.4 \mathrm{kPa}(55$ $\mathrm{mm} \mathrm{Hg}$ ) after pleural aspiration had re-expanded the right lung. Four hours before death the $\mathrm{PaO}_{2}$ was $6.9 \mathrm{kPa}(51 \mathrm{~mm} \mathrm{Hg}), \mathrm{PaCO}_{2} 4.3 \mathrm{kPa}(32 \mathrm{~mm}$ $\mathrm{Hg}$ ), and $\mathrm{pH} \mathrm{7.33.}$

\section{Perfusion scan}

This was first done in November 1974 four days after the lung function tests shown in Table 1. No pleural fluid was seen on the chest radiograph, even in the right lateral decubitus position. The scan was obtained after the intravenous injection of $4.2 \mathrm{mCi}$ of $99 \mathrm{~m}$-technetium-labelled albumin macroaggregates with diameters of $20-60 \mu \mathrm{m}$. To minimise any effect on the pulmonary image of occult pleural fluid, the particles were injected in the seated position, whereas anterior and posterior scans were obtained from the anterior aspect while she lay supine. Using this procedure even moderate-sized effusions cause only minor defects at the lung base (Mishkin and Brashear, 1970). A scan of the whole trunk is shown in Fig. 1. There had been less uptake of particles throughout the right lung compared with the left lung. Also some of the particles had passed through the lungs into the systemic circulation, causing high scintillation count rates over abdominal organs. The appearances were consistent with intrapulmonary arteriovenous shunts predominantly within the right lung. A second scan in April 1976 was very similar.

\section{Postmortem findings}

Two hours after death a coroner's postmortem examination was performed. The liver and spleen were moderately enlarged and there was a small amount of ascites. No excess fluid was present in the pleural cavities and there were few pleural adhesions on either side in spite of the instillation of talc the year before. The lungs and diaphragm were removed for further studies, and blocks of fresh tissue were cut from each lung for subsequent electron microscopy.

No gross pulmonary abnormalities were observed, but their combined weight of $1040 \mathrm{~g}$ was more than is usual for white females (745 $\mathrm{g} \pm 91$ SD) (Whimster and MacFarlane, 1974).

\section{PREPARATION}

The lungs were prepared for quantitative morphometric analysis using previously described techniques (Elliott and Reid, 1965; Davis and Reid, 1970). In brief, the pulmonary arterial tree was injected with a micropaque-gelatin suspension at $65^{\circ} \mathrm{C}$ and at a pressure of $10 \mathrm{kPa}\left(100 \mathrm{~cm} \mathrm{H}_{2} \mathrm{O}\right)$. The injected material distends and fills all arteries greater than $15 \mu \mathrm{m}$ in diameter but does not cross the capillary bed; its passage into pulmonary 


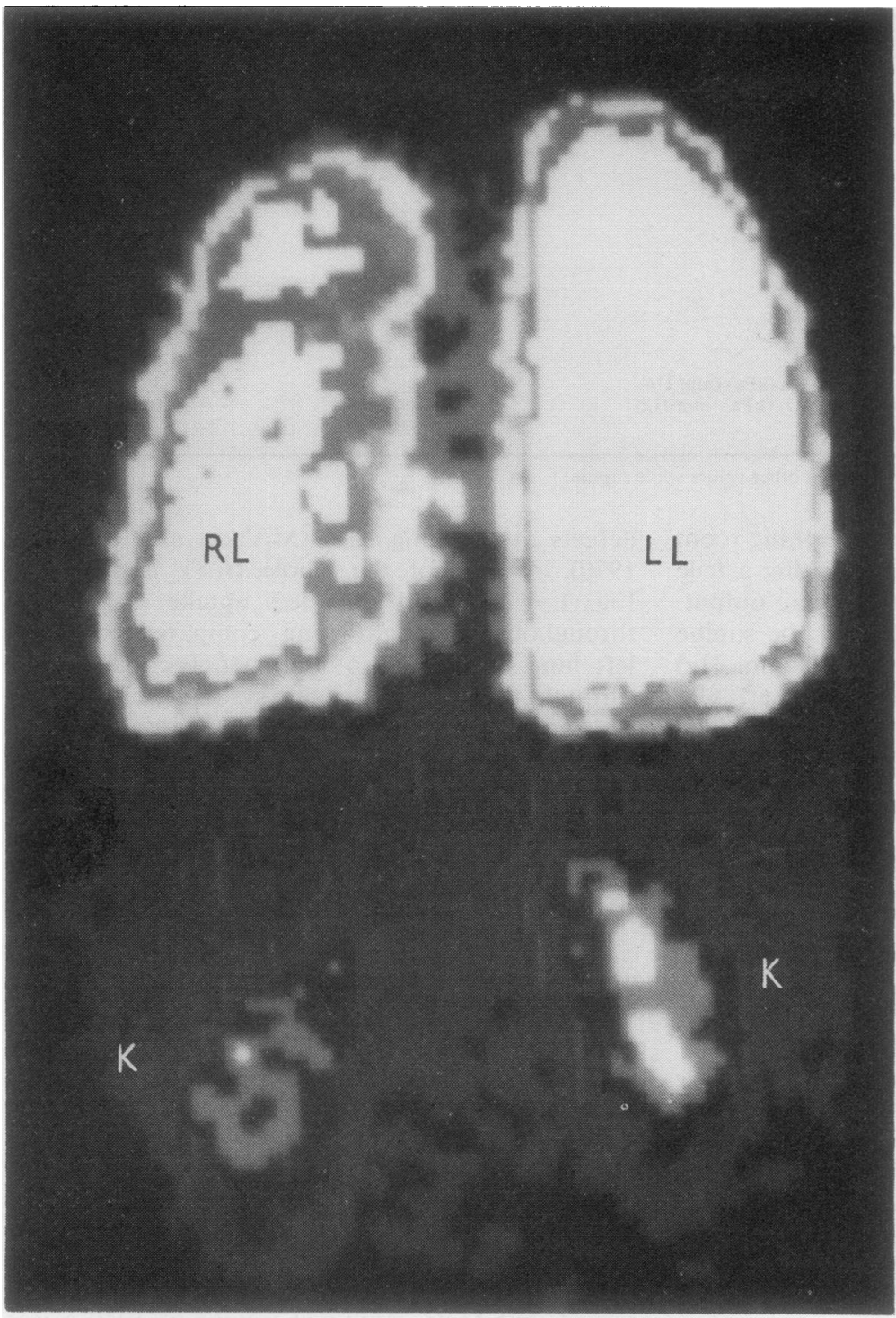

Fig. 1 Monochrome photograph of a posterior colour scan of the trunk after the intravenous injection of 99-technetium-labelled albumin macro-aggregates. The right lung $(R L)$ has taken up fewer of the particles than the left lung $(L L)$, and their passage through abnormal intrapulmonary arteriovenous communications to the systemic circulation is demonstrated by the high count rates over the kidneys $(K)$.

veins indicates the presence of arteriovenous anastomoses. After vascular injection the lungs were inflated through the trachea with $10 \%$ formol saline at a pressure of $4.5 \mathrm{kPa}\left(45 \mathrm{~cm} \mathrm{H}_{2} \mathrm{O}\right)$ until the pleura was tense. After fixation the lungs were radiographed and the preacinar arterial size was assessed by measuring on the radiograph the internal diameter of the largest artery in the lower lobe at 10 equal intervals along its axial pathway from the hilum to the periphery. Eight blocks of tissue were then taken from each lung using a stratified random sampling technique (Dunnill, 1962), and
$4 \mu \mathrm{m}$ sections were cut and stained with Verhoff's elastic van Gieson. After a general histological N assessment, a quantitative microscopic analysis of $\sigma$ the small vessels was performed. The average diameters of arteries adjacent to respiratory bron- $\frac{}{0}$ chioles and alveolar ducts were calculated. As? another index of vessel size population counts were done on arteries less than $300 \mu \mathrm{m}$ in diameter $\overrightarrow{0}$ (Hislop and Reid, 1972), whereby the relative in- $\overrightarrow{\mathbb{D}}$ cidence of muscular, partially muscular, and non- $\vec{D}$ muscular vessels was determined in relation to arterial diameter. The total numbers of filled 
arteries and alveoli were also counted in a unit area and expressed as a ratio of number of arteries to number of alveoli. Control data were obtained using the lungs of four individuals who had died without liver or lung disease. For further study of small intra-acinar vessels random samples were taken from the injected lungs and embedded in Araldite. Using an LKB III ultramicrotome and glass knives, $1 \mu \mathrm{m}$ sections were cut, which were stained with toluidine blue in $1 \%$ borax and studied by light microscopy.

The lung tissue which had been obtained soon after death for electron microscopy was fixed in $2.5 \%$ glutaraldehyde in cacodylate buffer for 2 hours, postfixed in $1 \%$ osmium tetroxide, dehydrated, and embedded in Araldite. Pale gold sections were cut and stained with methanolic uranyl acetate followed by lead citrate (Reynolds, 1963).

MACROSCOPIC AND RADIOGRAPHIC APPEARANCES During vascular injection many abnormal pleural vessels resembling cutaneous spider naevi were filled with the micropaque gelatin, as shown in Fig. 2. The naevi were more numerous over the right than the left lung and provided a striking contrast with the vessel-free appearance of the pleural surface after vascular injection of normal lungs. There was no reflux of injected material from the pulmonary veins at the hilum, suggesting that no major arteriovenous anastomoses were present. Likewise no arteriovenous communications or filling of large veins were visible on the radiographs; these also showed that the preacinar arterial diameter was normal.

\section{LIGHT MICROSCOPY}

The lung architecture appeared normal and no direct communications were seen between large arteries and veins. Nonetheless injected material was visible in some of the small veins, especially in the right lung, which were identified by their peripheral position in connective tissue of the interlobular septa and by the absence of an accompanying airway (Fig. 3). The venous filling demonstrated the existence of arteriovenous anastomoses and was not observed in any of the control lungs; its limitation to the small veins suggested that the anastomoses were at precapillary level. Another abnormality was dilatation of all intra-acinar arteries, and this was more pronounced in the right lung, as shown by the results in Table 2. Statistical comparisons showed that in each lung

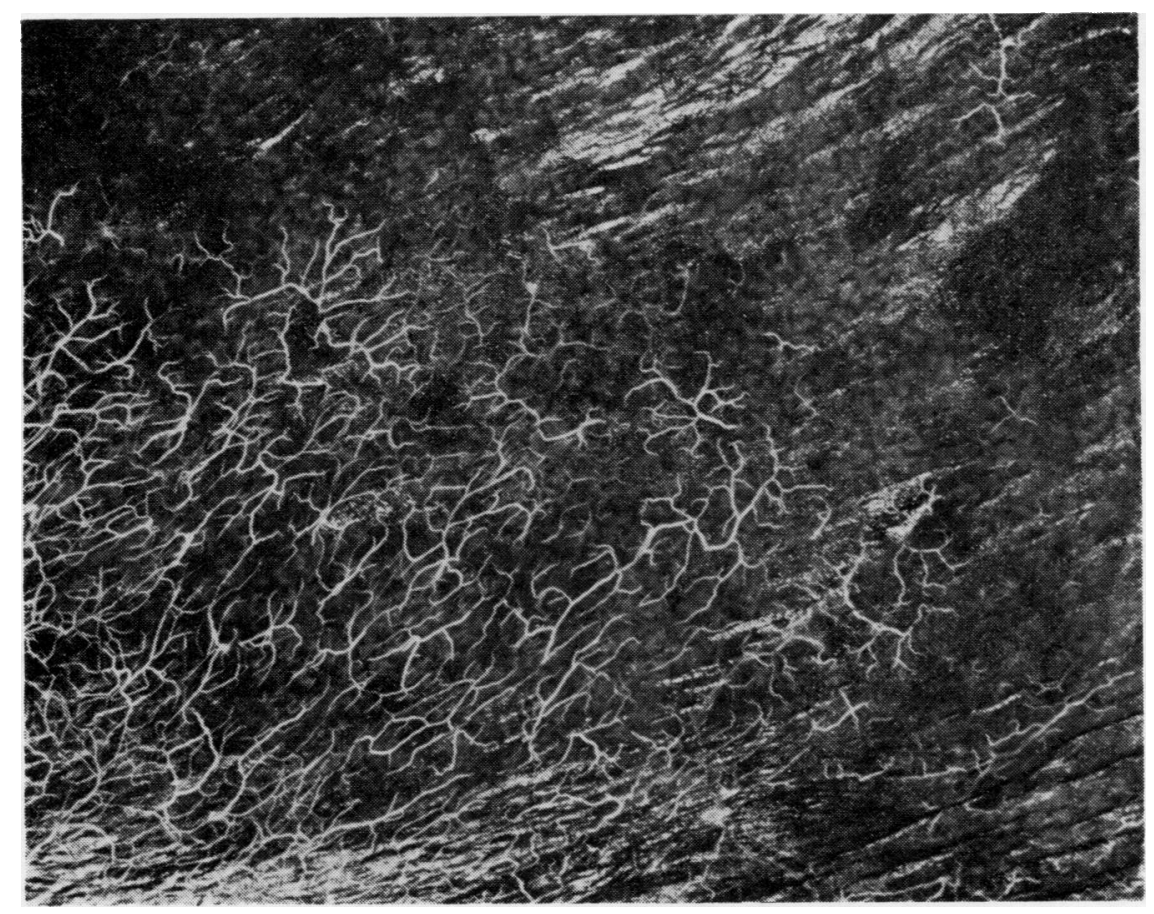

Fig. 2 Macroscopic appearance of the right lung's pleural surface showing numerous spider naevi filled with micropaque gelatin. 


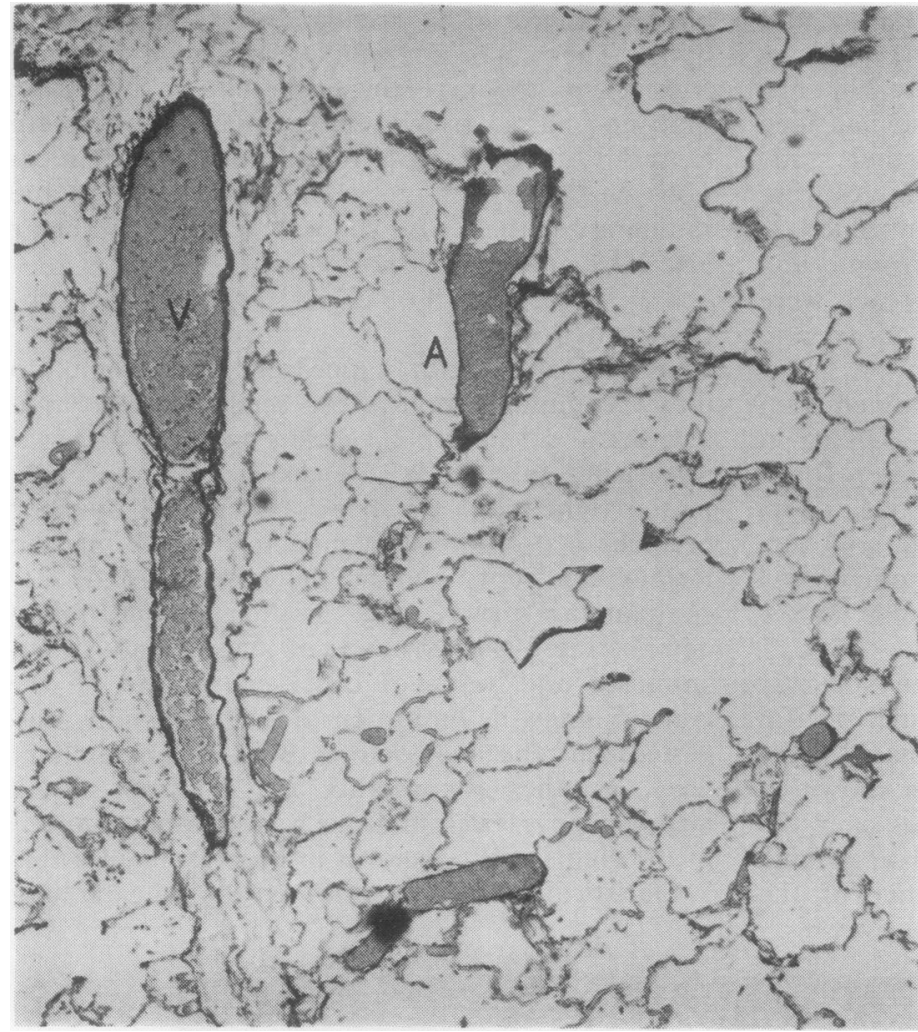

Fig. 3 Photomicrograph of a lung section showing injection material filling an artery $(A)$ adjacent to an alveolar duct and also a small vein $(V)$ in an interlobular septum. The venous filling indicates the presence of intrapulmonary arteriovenous anastomoses (Elastic van Gieson $\times 55)$.

Table 2 Diameter $(\mu \mathrm{m})$ of small arteries categorised by adjacent airway

\begin{tabular}{llll}
\hline Adjacent airway & Left lung & Right lung & Control lungs \\
\hline Respiratory & $265 \pm 100$ & $321 \pm 120$ & $178 \pm 30$ \\
bronchiole & $(\mathrm{n}=28)$ & $(\mathrm{n}=49)$ & $(\mathrm{n}=55)$ \\
Alveolar duct & $155 \pm 50$ & $165 \pm 56$ & $88 \pm 17$ \\
& $(\mathrm{n}=51)$ & $(\mathrm{n}=64)$ & $(\mathrm{n}=95)$ \\
\hline
\end{tabular}

Values given as mean $\pm \mathrm{SD}$.

the mean arterial diameters measured at respiratory bronchiolar or alveolar duct level were significantly greater than in control lungs $(P<0.001)$. The arterial diameters in the right lung were significantly greater than in the left lung when vessels were compared adjacent to respiratory bronchioles $(0.001<\mathrm{P}<0.01)$, but not when those next to alveolar ducts were compared $(0.3<\mathrm{p}<$ $0.4)$. As further evidence of vasodilatation, there was an increase in the proportion of non-muscular and partially muscular arteries in the intra-acinar arterial population when grouped by diameter (Fig. 4); this increase was more pronounced in the right lung. The number of arteries per alveolus was within normal limits. Examination of the toluidine blue sections (Fig. 5) revealed unexpected abnormalities in the small veins and capillaries. Unlike the arteries, the small veins did not seem dilated; their luminal diameter actually appeared diminished due to thickening of their walls with a pale-staining, homogeneous, and acellular material. Similar changes were observed in capillaries, but the arterial walls seemed normal.

\section{ELECTRON MICROSCOPY}

Ultrastructural examination demonstrated that the $\widetilde{N}$ increased thickness of the walls of small veins was $N$ mainly due to a layer of collagen fibres and fine $N$ filamentous material, as shown in Fig. 6. The $\underset{\sigma}{\sigma}$ collagen was surrounded by an interrupted elastic lamina, suggesting that it was located within the intima. However, the possibility of its representing $\stackrel{\oplus}{\oplus}$ medial degeneration could not be excluded since there were occasional deposits of elastin and a 0 few degenerating smooth muscle cells both within $\underset{\mathbb{D}}{\mathbb{D}}$ and internal to the collagen layer. The basement $\stackrel{\mathbb{D}}{\mathbb{D}}$ membrane also appeared slightly thickened. Many capillary walls were similarly thickened with col- 


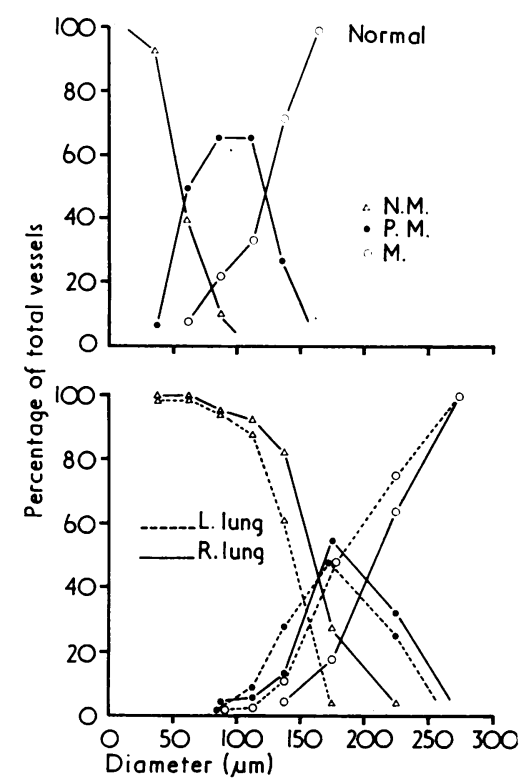

Fig. 4 Arterial population counts. Percentage fractions of muscular $(M)$, partially muscular $(P M)$, and non-muscular $(N M)$ vessels within arterial populations grouped by diameter are shown for the normal lung (upper panel) and each of the patient's lungs (lower panel). Note the rightward shift of the curves in the patient's lungs, which affects her right more than her left lung. This indicates that the transition between each structural type of vessel is occurring at an abnormally large diameter due to pulmonary vasodilatation.

lagen (Fig. 7). As a result of these changes the minimum blood-gas distance was increased up to $0.96( \pm 0.11$ SEM) $\mu \mathrm{m}$ compared with 0.53 $( \pm 004) \mu \mathrm{m}$ in normal lung sections $(P<0.001)$. Desquamation of epithelial cells was widespread, and the blood-gas distance would have been greater still if an intact epithelial layer had been included in the patient's measurements. In addition, alveolar oedema fluid was often seen as a film coating the surface of the alveolar spaces, thereby further increasing the blood-gas barrier.

\section{Discussion}

\section{GAS EXCHANGE AND LUNG VASCULATURE}

\section{Summary of findings}

The physiological studies showed that our patient's hypoxaemia was due to impaired pulmonary gas exchange with a large right-to-left shunt and a low TF. Evidence of pulmonary arteriovenous shunts was obtained in vivo by perfusion scanning; radio- active particles were able to pass through the lungs even though larger than normal capillary diameter. The shunts seemed unevenly distributed because fewer particles impacted in the right than in the left lung. Pulmonary arterial injection at necropsy demonstrated the existence of precapillary arteriovenous anastomoses within the lungs and pleural spider naevi. A morphometric analysis showed dilatation of small pulmonary arteries. Large arteries were normal in size. The vascular changes were more marked in the right lung. The walls of pulmonary capillaries and venules were thickened by a layer of collagen.

\section{Sites of shunting}

Physiological evidence of right-to-left shunt in liver cirrhosis was first presented by Wilson et al. (1953), but its anatomical basis has been a subject of controversy. Rydell and Hoffbauer (1956) demonstrated multiple intrapulmonary arteriovenous anastomoses with diameters of up to $1000 \mu \mathrm{m}$ at necropsy in a boy with juvenile cirrhosis, which were sufficient to explain his cyanosis before death. Anastomoses were found between large arteries and veins near the hilum as well as in the peripheral vascular bed. Similar findings were reported in two other cases where cirrhosis had developed in early life (Hales, 1956; Kravath et al., 1971). In contrast, several postmortem studies in older patients failed to identify an obvious anatomical pathway for shunting and suggested that it might be occurring at an extrapulmonary site (Rodman et al., 1959; Georg et al., 1960). With hindsight, it now seems more likely in these instances that the techniques had been inadequate for demonstrating small anastomoses within the acinus. Although channels linking the portal and pulmonary venous systems (Calabresi and Abelmann, 1957) offer an alternative shunt pathway it carries insufficient blood flow to cause more than trivial changes in arterial $\mathrm{O}_{2}$ saturation (Nakamura et al., 1965).

\section{Intrapulmonary shunts}

Further investigations in the past decade have reemphasised that abnormal intrapulmonary arteriovenous communications are the most important cause of shunting even in adult cases of cirrhosis. Perfusion scans done in such patients have always shown that the lungs fail to trap large proportions of intravenously injected particles (Stanley et al., 1972; Robin et al., 1975). However, in cases with arteriovenous anastomoses demonstrated postmortem using micropaque gelatin, communications between pre-acinar vessels have been visualised in only one patient, the child re- 


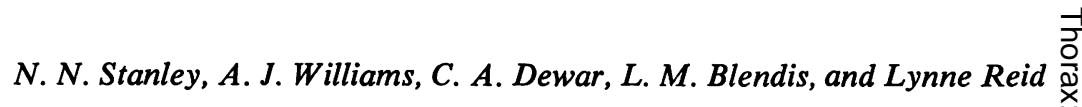

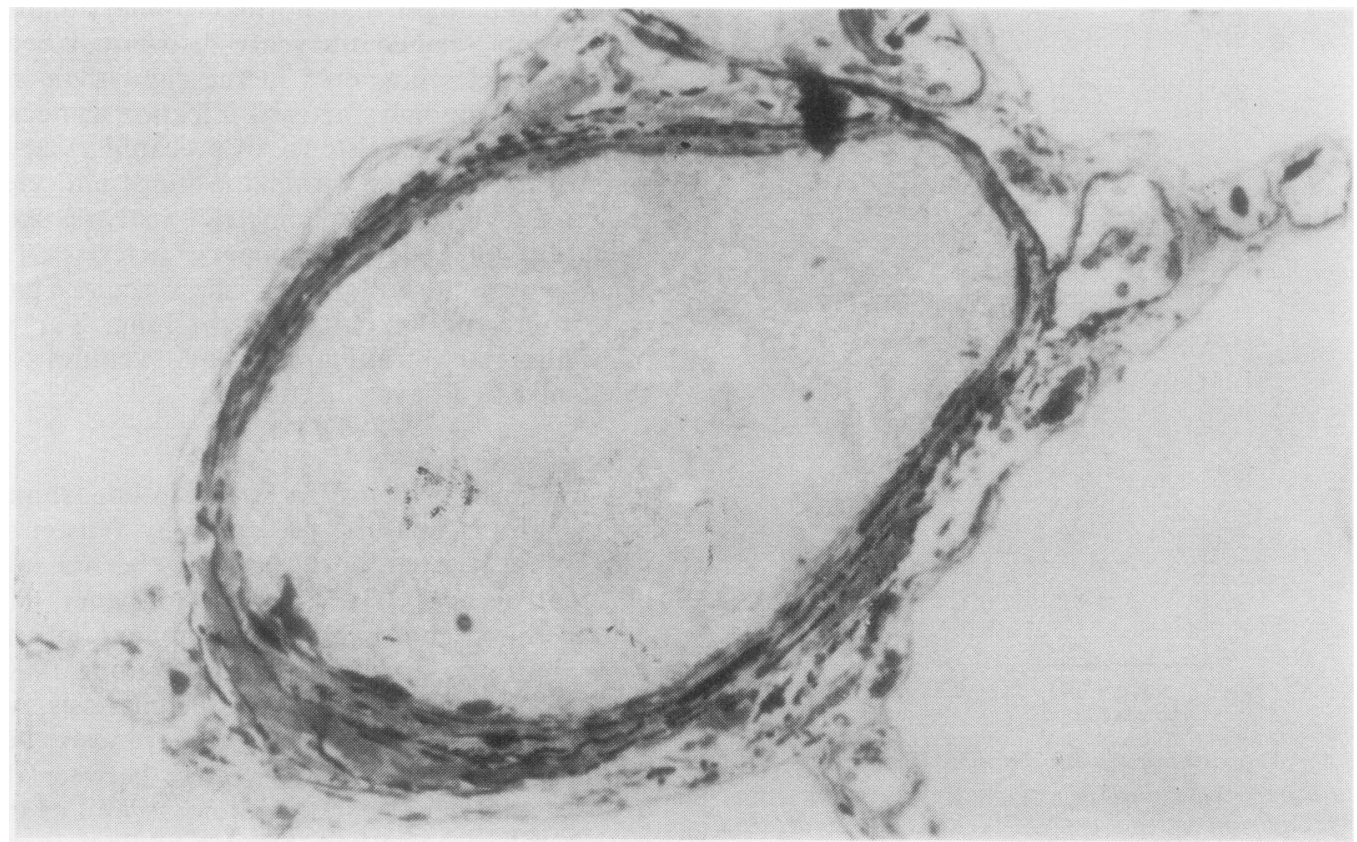

(a)

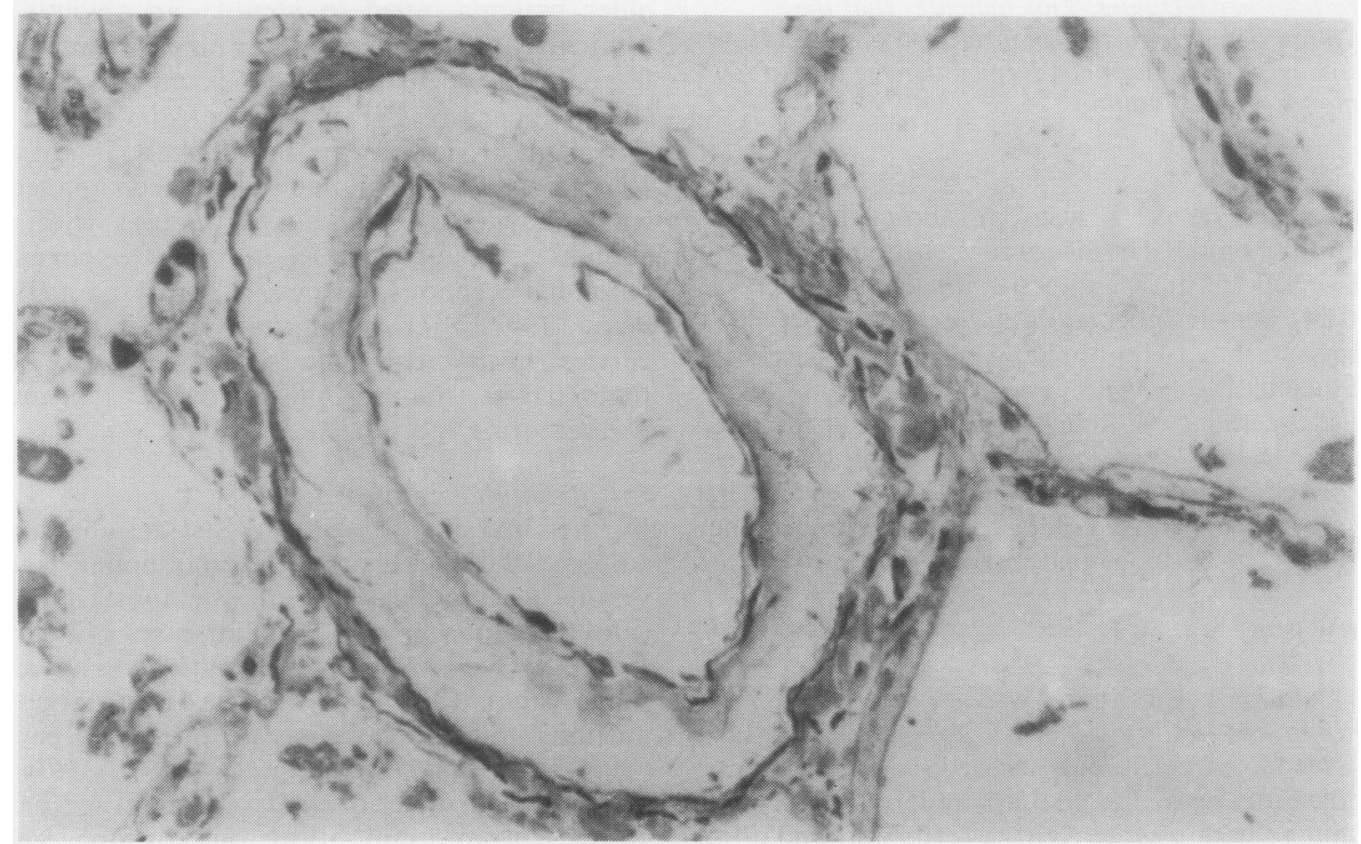

(b)

Fig. 5

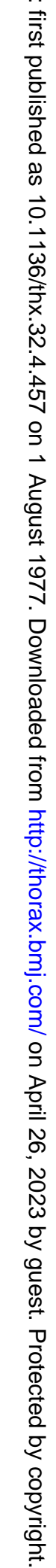




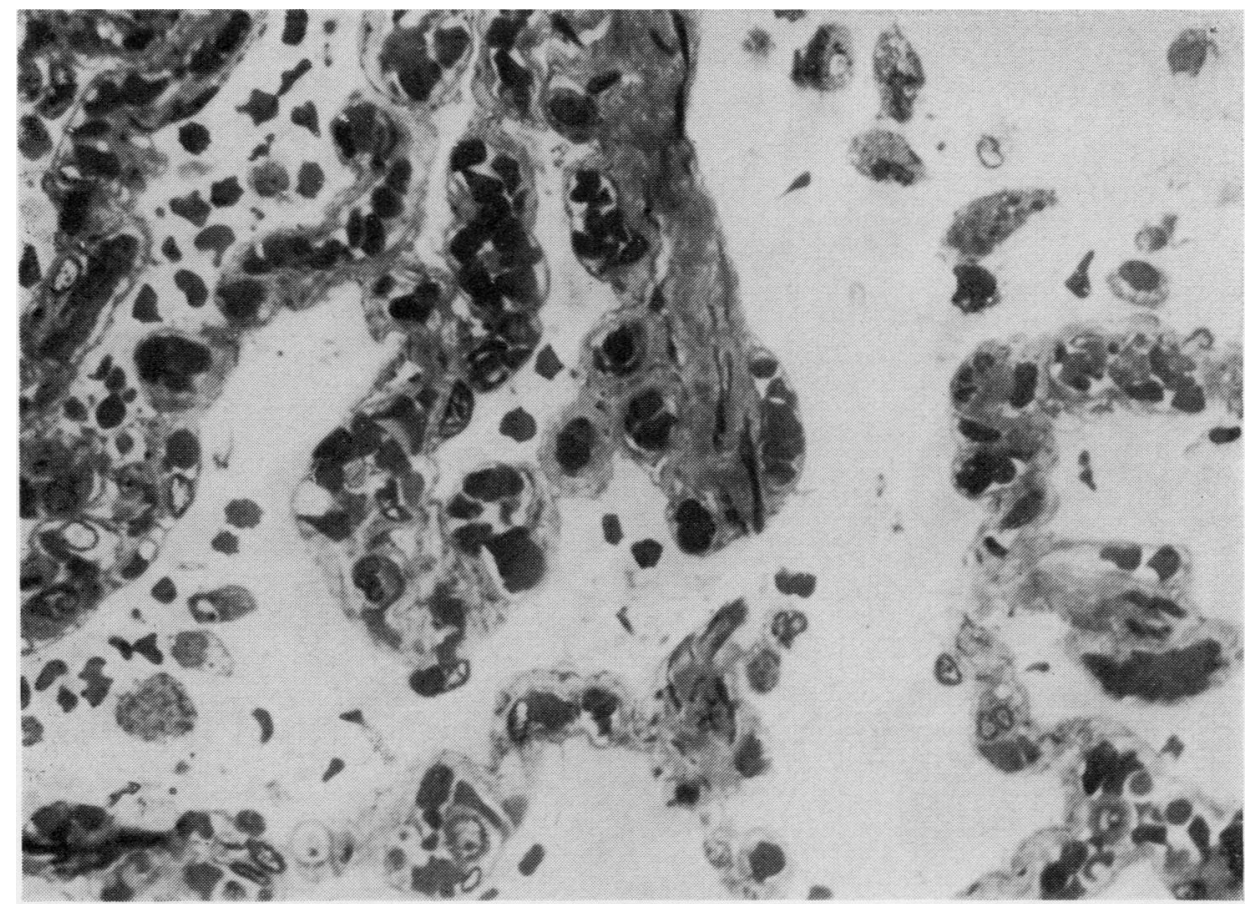

(c)

Fig. 5 Photomicrographs of $1 \mu \mathrm{m}$ sections: (a) Small artery showing normal wall thickness (injected lung); (b) Small vein with its wall thickened by amorphous material internal to the elastic lamina (injected lung); (c) Similar thickening is seen in walls of some capillaries containing red blood cells (uninjected lung) (Toluidine blue $\times 570)$.

ported by Kravath et al. (1971), and not in four others including the present case (Berthelot et al., 1966; Karlish et al., 1967; Silverman et al., 1968). Therefore shunting is rarely attributable to channels between large vessels remote from a gas exchanging surface, except possibly in children; more usually it reflects small precapillary anastomoses within the acinus. These may develop through dilatation of some normal capillaries to precapillary diameter or alternatively by the opening of anatomic precapillary anastomoses, which may exist in a non-functioning form in the normal lung (Tobin, 1966; Niden and Aviado, 1956). All intra-acinar vessels are capable of gas exchange due to the proximity of alveolar gas (Staub, 1961), but $\mathrm{O}_{2}$ uptake is thought to be very slow in precapillaries (Sackner et al., 1964) and anastomoses at this level are likely to behave as shunts even in hyperoxia. Not all hypoxic cases have precapillary anastomoses when studied at necropsy (Berthelot et al., 1966), but arterial unsaturation in liver cirrhosis may also be caused by ventilationperfusion inequality without shunting (Cotes $e t$ al.,
1968), perhaps on the basis of airway closure due to peribronchial oedema (Ruff et al., 1971). It has also been postulated that incomplete blood-gas $\mathrm{O}_{2}$ equilibration (partial shunting) may occur at capillary level, since the intra-acinar vascular disorder may cause extreme variation in diffusionperfusion ratios (Schomerus et al., 1975).

\section{Regional variation in shunting}

It was of additional interest that shunting appeared to be greater in the right than in the left lung. This conclusion was based on both lung scan appearances and pathological findings but was also consistent with physiological observations that the $\mathrm{PaO}_{2}$ rose when she lay on the left side and during partial collapse of the right lung after the diagnostic pneumoperitoneum. Presumably gravitational effects in left lateral recumbency and the presence of a right-sided pneumothorax improved gas exchange by causing preferential perfusion of the more efficient left lung. The possibility of leaving a permanent pneumothorax as a therapeutic manoeuvre was considered but discarded 


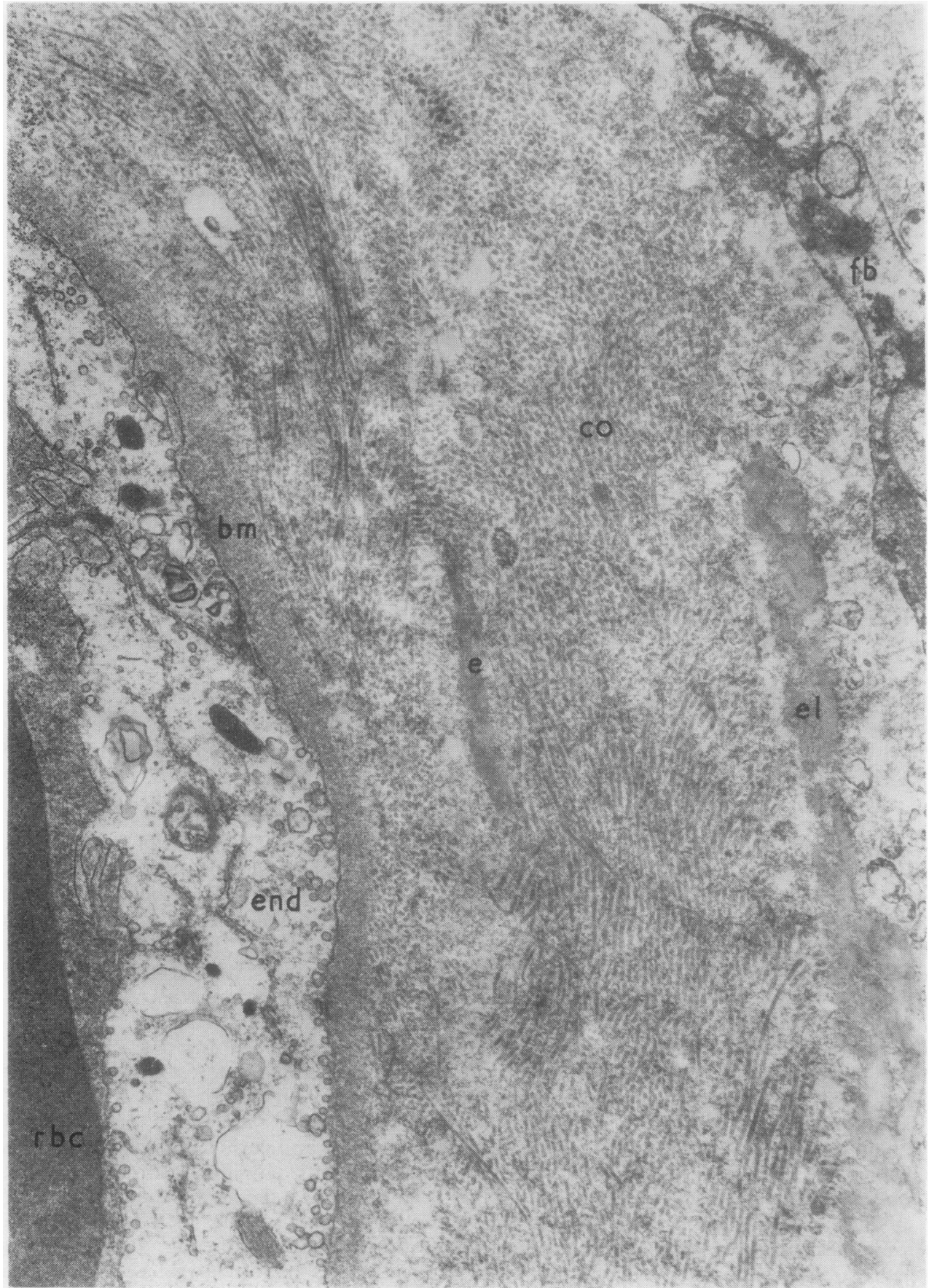

Fig. 6 Electron micrograph showing thickened wall of a small vein (external diameter $40 \mu \mathrm{m}$ ). The thickening is due to collagen (co) interspersed with some fine filaments. Elastin (e) is also present. Other features include a red blood cell (rbc), endothelium (end), basement membrane $(\mathrm{bm})$, part of a fibroblast $(\mathrm{fb})$, and elastic lamina $(\mathrm{el})(\times 18750)$. 


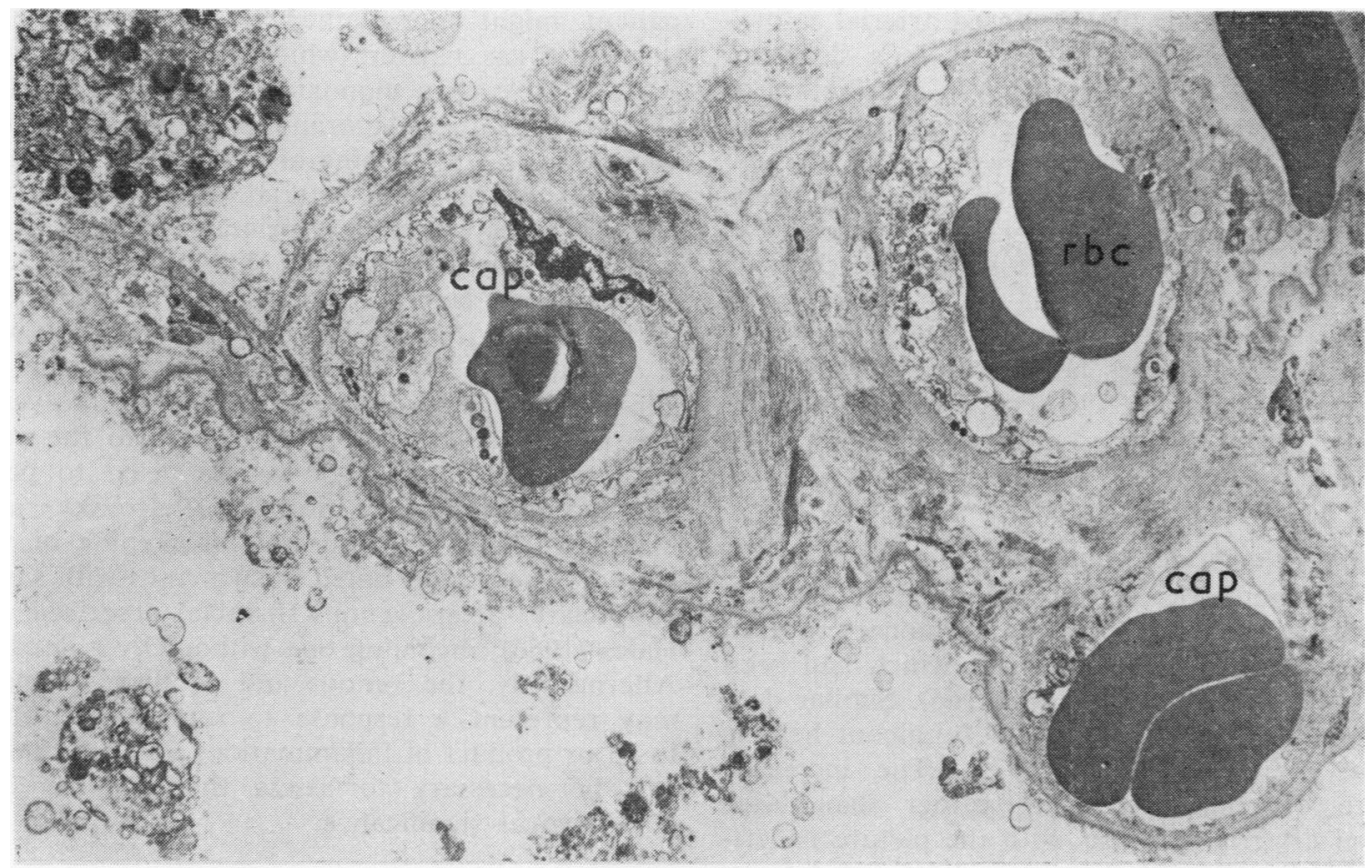

(a)

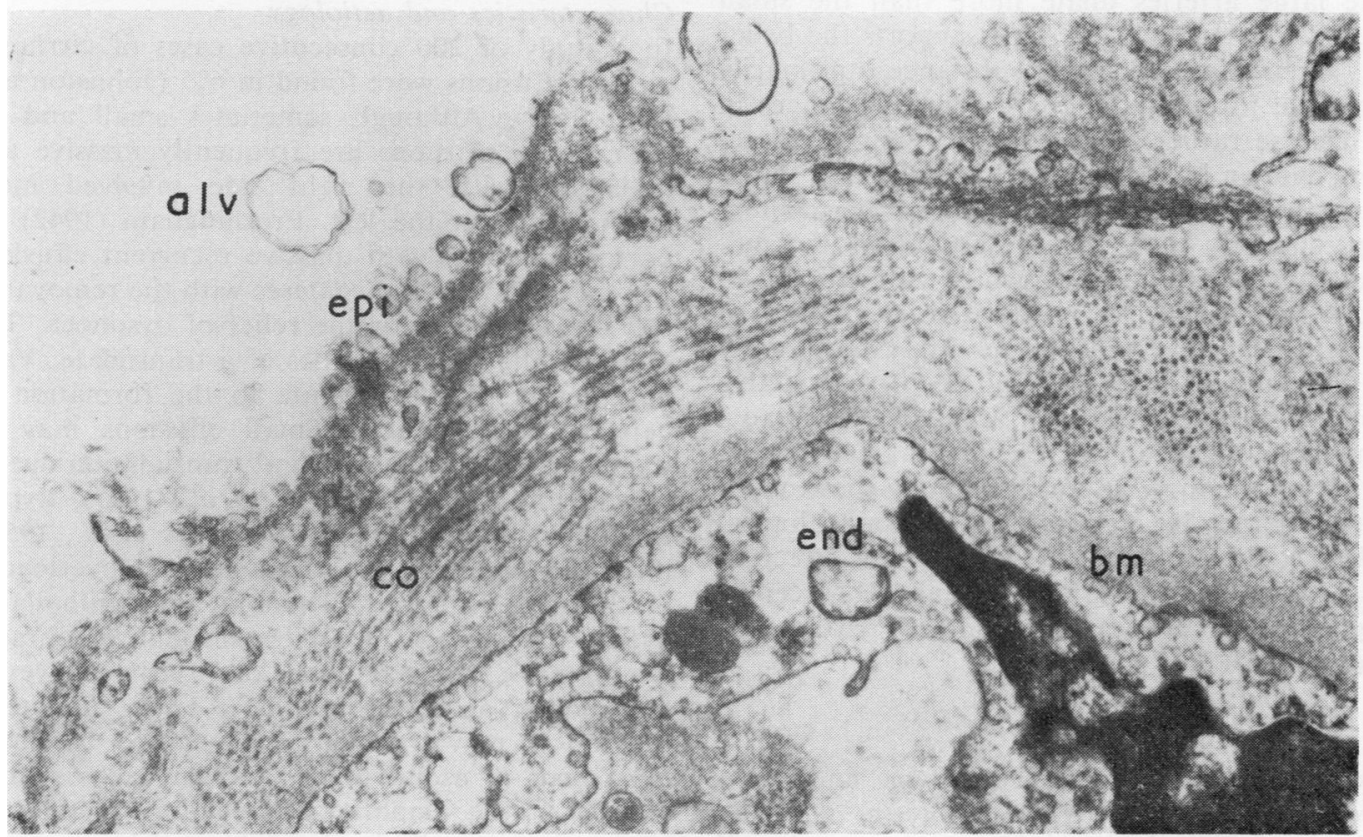

(b)

Fig. 7 (a) Electron micrograph of an alveolar wall showing capillaries (cap) with red blood cells $(r b c)$. Note the thickening of the capillary walls $(\times 5250)$. (b) Higher power view showing that the thickening largely consists of collagen (co). Endothelium (end), basement membrane (bm), alveolar space (alv), and epithelial cell debris (epi) are also indicated $(\times 22500)$. 
because, in spite of the increased arterial saturation, the respiratory stimulus of lung deflation made her more breathless. Uneven distribution of intrapulmonary shunting has previously been noted in a cyanosed patient with active chronic hepatitis whose perfusion scan and pulmonary angiogram suggested relative localisation of intrapulmonary shunts to the left lower lobe (Stanley et al., 1972). Regional variation in the size and density of arteriovenous anastomoses may also explain the differences betwen lobes in the time for injected material to cross the pulmonary vascular bed in the case reported by Karlish et al. (1967).

\section{Pulmonary arterial dilatation}

The morphometric analysis has provided the first quantitative evidence that the pulmonary arterial tree is dilated in liver cirrhosis, which had been suggested by Berthelot et al. (1966). Similar data have been obtained in cases of fulminant hepatic failure (Williams et al., 1976). The increased calibre of small peripheral rather than large central arteries contrasts with the picture in leftto-right shunting due to congenital heart defects, where large arteries dilate more than the small ones (Hislop et al., 1975). This supports the belief that a circulating vasoactive substance is primarily responsible for the pulmonary arterial changes in liver disease rather than passive distension to accommodate an increased blood flow. Pleural spider naevi and precapillary anastomoses within the lung are presumably other manifestations of the pulmonary vasodilatation. Possible vasoactive substances responsible for the circulatory changes in liver failure include reduced ferritin (Shorr et al., 1951), histamine (Martini et al., 1970), vasoactive intestinal peptide (Said and Mutt, 1970), bradykinin, and prostaglandins (Seymour et al., 1976). Identifying the most important among these might assist in therapy if an appropriate pharmacological blocker could be given. Regarding the effect of histamine, trials of histamine $\mathrm{H}_{1}$ - and $\mathrm{H}_{2}$-receptor antagonists did not cause significant changes in our patient's $\mathrm{PaO}_{2}$.

\section{Vascular basis of reduced $T F$}

A reduction in TF is a consistent finding in hypoxic cases of liver cirrhosis (Cotes et al., 1968; Stanley and Woodgate, 1972). It occurs in all types of chronic liver disease and not just in cases with a history of alcoholism or smoking, which may be independent causes of a reduced TF (Emirgil et al., 1974; Van Ganse et al., 1972). Its aetiology has previously been obscure but, in our patient, might be explained by the thickening of the blood-gas barrier, which must have slowed the rate of carbon monoxide diffusion across the alveolar-capillary membrane. We have since discovered mural thickening of capillaries and small veins, associated with arterial dilatation, in two other patients who died of primary and secondary biliary cirrhosis respectively, but not in 12 cases of fulminant hepatic failure reported elsewhere (Williams et al., 1976). Possibly the thickening was a consequence of long-standing transmission of abnormally high pressures to capillaries and veins due to arterial dilatation, analogous to the progressive arterialisation of vessels distal to peripheral arteriovenous fistulae (Petrovsky and Milonov, 1967). Focal intimal thickening of venous walls was also noted in two cases with small pulmonary arteriovenous fistulae described by Hales (1956), including one without liver disease. Alternatively, the venous and capillary changes may represent a response to some unidentified toxin or product of inflammation. Further studies will be necessary to assess their nature and physiological significance.

\section{HEPATIC HYDROTHORAX \\ Characteristics and aetiology}

In a study of 200 consecutive cases of cirrhosis, pleural effusions were found in $6 \%$ (Johnston and Loo, 1964). Although sometimes small and bilateral, the effusions are frequently massive and unilateral with the right side involved more frequently than the left. Frothingham (1942) reported a patient with massive recurrent effusions who needed 211 thoracenteses with the removal of 467 litres of fluid for the relief of dyspnoea. The fluid has the characteristics of a transudate. Various factors may contribute to the formation of hepatic hydrothoraces. Small effusions may be the result of excessive pleural transudation due to hypoalbuminaemia (Higgins et al., 1947), hypertension in the azygos vein (Morrow et al., 1958), increased pressure in a thoracic duct overloaded by drainage of ascites (Dumont and Mulholland, 1960), and passage of ascites through diaphragm lymphatics (Johnston and Loo, 1964). However, the sudden accumulation of a large, unilateral effusion is now thought to be caused by direct movement of ascites under pressure across small defects in the diaphragm. Openings in the diaphragm can usually be demonstrated by means of 0 a diagnostic pneumoperitoneum (Williams, 1950; Lieberman et al., 1966) and have been observed at necropsy in several cases (Emerson and Davies, 1955; Lieberman and Peters, 1970). The defects are probably created by the rupture of congenital 


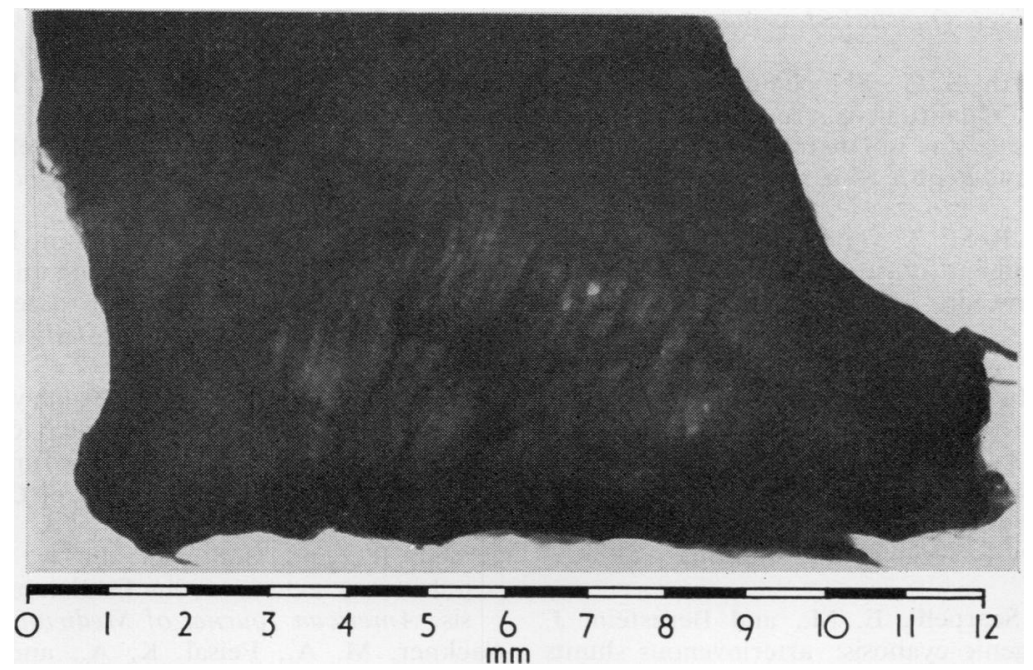

Fig. 8 Thoracic surface of transilluminated diaphragm showing areas of thinning within the central tendon.

sites of weakness. Although no openings were found post mortem in our patient's diaphragm, there were many weak areas within the central tendon which might have ruptured under moderate stress (Fig. 8).

\section{Therapy}

The formation of a hepatic hydrothorax decompresses the abdomen, which may allow a diaphragmatic opening to heal (Lieberman and Peters, 1970). Therefore thoracentesis should be reserved for diagnosis and relief of dyspnoea. since it may re-establish a large transdiaphragmatic pressure gradient and prevent healing. The principal aim of therapy should be the elimination of ascites because this is the source of the hydrothorax. Often conventional medical treatment is sufficient, but sometimes large hydrothoraces may be a recurrent problem in spite of the intensive use of diuretics. Unfortunately, the potential value of chemical pleurodesis in such instances cannot be judged from the results in the present case, since failure to produce a long-lasting remission could be explained by an inadequate pleural reaction to the sclerosing agent.

\section{References}

Berthelot, P., Walker, J. G., Sherlock, S., and Reid, L. (1966). Arterial changes in the lungs in cirrhosis of the liver-lung spider nevi. New England Journal of Medicine, 274, 291-298.

Calabresi, P., and Abelmann, W. H. (1957). Portocaval and porto-pulmonary anastomoses in Laen- nec's cirrhosis and in heart failure. Journal of Clinical Investigation, 36, 1257-1265.

Cotes, J. E. (1975). Lung Function, 3rd edition. Blackwell Scientific Publications, Oxford.

Cotes, J. E., Field, G. B., Brown, G. J. A., and Read, A. E. (1968). Impairment of lung function after portacaval anastomosis. Lancet, 1, 952-955.

Davis, G. M., and Reid, L. (1970). Growth of the alveoli and pulmonary arteries in childhood. Thorax, 25, 669-681.

Dumont, A. E., and Mulholland, J. H. (1960). Flow rate and composition of thoracic-duct lymph in patients with cirrhosis. New England Journal of Medicine, 263, 471-474.

Dunnill, M. S. (1962). Quantitative methods in the study of pulmonary pathology. Thorax, 17, 320-328.

Elliott, F. M., and Reid, L. (1965). Some new facts about the pulmonary artery and its branching pattern. Clinical Radiology, 16, 193-198.

Emerson, P. A., and Davies, J. H. (1955). Hydrothorax complicating ascites. Lancet, 1, 487-488.

Emirgil, C., Sobol, B. J., Heymann, B., and Shibutani, K. (1974). Pulmonary function in alcoholics. American Journal of Medicine, 57, 69-77.

Frothingham, J. R. (1942). Cirrhosis of the liver complicated by persistent right hydrothorax and ascites. New England Journal of Medicine, 226, 679-682.

Georg, J., Mellemgaard, K., Tygstrup, N., and Winkler, K. (1960). Venoarterial shunts in cirrhosis of the liver. Lancet, 1, 852-854.

Hales, M. R. (1956). Multiple small arteriovenous fistulas of the lungs. American Journal of Pathology, 32, 927-937.

Higgins, G., Kelsall, A. R., O'Brien, J. R. P., Stewart, A. M., and Witts L. J. (1947). Ascites in chronic 
diseases of the liver. Quarterly Journal of Medicine, 16, 263-274.

Hislop, A., Haworth, S. G., Shinebourne, E. A., and Reid, L. (1975). Quantitative structural analysis of pulmonary vessels in isolated ventricular septal defect in infancy. British Heart Journal, 37, 1014 1021.

Hislop, A., and Reid, L. (1972). Intra-pulmonary arterial development during fetal life-branching pattern and structure. Journal of Anatomy, 113, 35-48.

Johnston, R. F., and Loo, R. V. (1964). Hepatic hydrothorax: studies to determine the source of the fluid and report of thirteen cases. Annals of Internal Medicine, 61, 385-401.

Karlish, A. J., Marshall, R., Reid, L., and Sherlock, S. (1967). Cyanosis with hepatic cirrhosis: a case with pulmonary arteriovenous shunting. Thorax, 22, 555-561.

Kravath, R. E., Scarpelli. E. M., and Bernstein, J. (1971). Hepatogenic cyanosis: arteriovenous shunts in chronic active hepatitis. Journal of Pediatrics, 78, 238-245.

Lieberman. F. L.. Hidemura, R., Peters, R. L., and Reynolds, T. B. (1966). Pathogenesis and treatment of hydrothorax complicating cirrhosis with ascites. Annals of Internal Medicine, 64, 341-351.

Lieberman, F. L., and Peters, R. L. (1970). Cirrhotic hydrothorax: further evidence that an acquired diaphragmatic defect is at fault. Archives of Internal Medicine, 125, 114-117.

Martini, G. A., Arndt, H., Baltzer, G., Buchta. I., Hardewig, A., Marsch, W., and Schmidt, H. A. (1970). Pulmonary circulation in portal hypertension. Annals of the New York Academy of Sciences, 170, 280-295.

Mishkin, F. S., and Brashear. R. E. (1970). An experimental study of the effect of free pleural fluid on the lung scan. Radiology, 97, 283-287.

Morrow, C. S., Kantor, M.. and Armen, R. N. (1958). Hepatic hydrothorax. Annals of Internal Medicine, 49, 193-203.

Nakamura, T., Nakamura. S.. Tazawa, T., Abe, S., Aikawa, T., and Tokita, K. (1965). Measurement of blood flow through portopulmonary anastomosis in portal hypertension. Journal of Laboratory and Clinical Medicine, 65, 114-121.

Niden, A. H., and Aviado, D. M., Jr. (1965). Effects of pulmonary embolism on the pulmonary circulation with special reference to arteriovenous shunts in the lung. Circulation Research, 4, 67-73.

Ogilvie, C. M., Forster, R. E., Blakemore, W. S.. and Morton, J. W. (1957). A standardized breath holding technique for the clinical measurement of the diffusing capacity of the lung for carbon monoxide. Journal of Clinical Investigation, 36, 1-17.

Petrovsky, B. V.. and Milonov, O. B. (1967). 'Arterialization' and 'venization' of vessels involved in traumatic arteriovenous fistulae: aetiology and pathogenesis. (An experimental study). Journal of Cardiovascular Surgery (Torino), 3, 396-407.

Reynolds, E. S. (1963). The use of lead citrate at high $\mathrm{pH}$ as an electron-opaque stain in electron microscopy. Journal of Cell Biology, 17, 208-212.

Robin, E. D., Horn, B., Goris, M. L., Theodore, J., Van Kessel, A., Mazoub, J., and Tilkian, A. (1975). Detection, quantitaticn and pathophysiology of lung 'spiders'. Transactions of the Association of American Physicians, 88, 202-216.

Rodman, T., Hurwitz. J. K., Pastor, B. H., and Close, H. P. (1959). Cyanosis, clubbing and arterial oxygen unsaturation associated with Laennec's cirrhosis. American Journal of the Medical Sciences, 238, 534-541.

Ruff, F., Hughes, J. M. B., Stanley, N., McCarthy, D., Greene, R., Aronoff, A., Clayton, L., and MilicEmili, J. (1971). Regional lung function in patients with hepatic cirrhosis. Journal of Clinical Investigation. 50, 2403-2413.

Rydell, R., and Hoffbauer, F. W. (1965). Multiple pulmonary arteriovenous fistulas in juvenile cirrhosis. American Journal of Medicine, 21, 450-460.

Sackner, M. A., Feisal. K. A., and Karsch, D. N. (1964). Size of gas exchange vessels in the lung. Journal of Clinical Investigation, 43, 1847-1855.

Said, S. I., and Mutt, V. (1970). Polypeptide with broad biological activity: isolation from small intestine. Science. 169, 1217-1218.

Schomerus, H., Buchta, I., and Arndt, H. (1975). Pulmonary function studies and oxygen transfer in patients with liver cirrhosis and different degree of portasystemic encephalopathy. Respiration, 32, 1-20.

Seymour. C. A., (for Neale, G., and Hughes, J. M. B.) (1976). Hepatogenous cyanosis and subarachnoid haemorrhage. Proceedings of the Royal Society of Medicine, 69, 59-60.

Shorr, E. D., Zweifach, B. W., Furchgott, R. F.. and Baez. S. (1951). Hepatorenal factors in circulatory homeostasis. IV. Tissue origins of the vasotropic principles, VEM and VDM, which appear during evolution of hemmorrhagic and tourniquet shock. Circulation, 3, 42-79.

Silverman, A., Cooper, M. D., Moller, J. H., and Good, R. A. (1968). Syndrome of cyanosis, digital clubbing, and hepatic disease in siblings. Journal of Pediatrics. 72, 70-80.

Stanley, N. N., Ackrill. P., and Wood, J. (1972). Lung perfusion scanning in hepatic cirrhosis. British Medical Journal, 4, 639-643.

Stanley. N. N., and Woodgate, D. J. (1971). The circulation, the lung, and finger clubbing in hepatic cirrhosis. British Heart Journal, 33, 469-472.

Stanley, N. N., and Woodgate, D. J. (1972). Mottled chest radiograph and gas transfer defect in chronic liver disease. Thorax. 27, 315-323.

Staub, N. C. (1961). Microcirculation of the lung using very rapid freezing. Angiology, 12, 469-472.

Tobin, C. E. (1966). Arteriovenous shunts in the peripheral pulmonary circulation in the human lung. Thorax, 21, 197-204.

Toghill, P. J.. Smith, P. G., Benton, P., Brown, R. C., and Matthews, H. L. (1974). Methyldopa damage. British Medical Journal, 3, 545-548.

Van Ganse, W. F., Ferris, B. G.. Jr., and Cotes, J. E. 
(1972). Cigarette smoking and pulmonary diffusing capacity (transfer factor). American Review of Respiratory Diseases, 105, 30-41.

Whimster, W. F., and MacFarlane, A. J. (1974). Normal lung weights in a white population. American Review of Respiratory Diseases, 110, 478-483.

Williams, A., Reid, L., Trewby, P. N., and Williams, R. (1976). Intrapulmonary vascular shunts in fulminant hepatic failure (Proceedings). Clinical Science and Molecular Medicine, 51, 6P

Williams, M. H. Jr. (1950). Pleural effusion produced by abdomino-pleural communication in a patient with Laennec's cirrhosis of the liver and ascites. Annals of Internal Medicine, 33, 216-221.

Wilson, R. H., Ebert, R. V., Borden, C. W., Pearson, R. T., Johnson, R. S., Falk, A., and Dempsey, M. E. (1953). The determinations of blood flow through nonventilated portions of the normal and diseased lung. American Review of Tuberculosis, 68, 177187.

Requests for reprints to: Dr. N. N. Stanley, Department of Medicine, The Middlesex Hospital, Mortimer Street, London W1N 8AA. 